\title{
APPROACH FOR SUSTAINABILITY CRITERIA AND PRODUCT LIFE- CYCLE DATA SIMULATION IN CONCEPT SELECTION
}

\author{
S. Y. Kwok ${ }^{凶}$, J. Schulte and S. I. Hallstedt \\ Blekinge Institute of Technology, Sweden \\ $\square$ sze.yin.kwok@bth.se
}

\begin{abstract}
Companies struggle with identifying relevant sustainability aspects strategically, assessing alternative solutions quantitatively, and making trade-offs. This paper reports results from a prescriptive study with an aerospace company, and presents the Sustainability Criteria And product life-cycle Data Simulation (SCADS) approach. Based on strategic integration of sustainability indicators, this approach aims to enable visualisation and comparison of the sustainability implications of different concepts in early design phases of product development.
\end{abstract}

Keywords: sustainable design, early design phase, simulation-based design, model-driven development, indicators

\section{Introduction}

With only 10 years left to reach the United Nations Sustainable Development Goals (United Nations, 2015), faster pace of change is anticipated in all areas of society. Product development companies play a key role in making the necessary transition happen, because they envision and develop new technologies, products, and business models, and this is where the majority of products' sustainability impact and social meaning in the larger system is determined (Gaziulusoy et al., 2013). However, the sustainability-driven change entails significant business risks, for example, reputation implications, stricter legislation and shifting customer demand. All of these can be turned into opportunities in terms of energising employees, reducing long-term costs, building resilient operations and supply chains, driving new innovations, being ahead of legislation, etc., resulting in competitive advantage (Chiu and Chu, 2012; Schulte and Hallstedt, 2018). Building capabilities for sustainable product development is, therefore, decisive for success and long-term survival, which is increasingly recognised by companies (Schulte and Hallstedt, 2017). Especially the early phases of product development, when ideas are generated and concepts are selected, are highly important, because this is where the direction of the following phases is set (McAloone and Tan, 2005).

However, there are numerous challenges with sustainability integration and implementation in the early phases of product innovation: (i) there is a vast number of support tools and methods for sustainable design (Bovea et al., 2012; Chiu and Chu, 2012), but knowledge and use of them is limited (Held et al., 2018); (ii) a strategic perspective is often missing (Hallstedt and Isaksson, 2017); (iii) a systems perspective is a prerequisite for effective work with sustainable product development (Broman et al., 2017), for instance to avoid sub-optimisation, but an organization also needs support to understand which sustainability aspects are particularly relevant for a specific product (Hallstedt, 2017); (iv) there 
are many interdependencies between different sustainability aspects and between sustainability aspects and other parameters, which results in difficult trade-off situations (Byggeth and Hochschorner, 2006); and (v) sustainability involves a qualitative dimension, which makes it difficult to quantify or monetise. Other challenges include time and data availability in early stages of engineering design to analyse sustainability in a rigorous manner without compromising the completeness of sustainability or the product life-cycle perspective (Schöggl et al., 2017). These challenges make it difficult to decide on which product concept is the best from a sustainability point of view alongside other values and risks.

To enhance acceptance and practical usage in industry, Ahmad et al. (2018) suggest to improve the maturity level of support tools and to meet the desired characteristics, which means developing tools that are easy to use, adaptable to different situations, and yield results that are easy to understand and communicate (Kwok and Hallstedt, 2018). Moreover, Ahmad et al. (2018) suggest future research to focus on the development of standard indicators, measurement procedures, measurement units and weighting of sustainability indicators for different engineering design problems. Another suggested focus area is the adoption of sustainable product development (SPD) tools for computer-based systems to increase their usability in industries.

In the light of the gap described above, the long-term vision of this research work is, therefore, to develop simulation support that helps finding the optimal concept from a multi-stakeholder value creation perspective, including sustainability. The purpose of this paper is to increase companies' capabilities and to provide decision-support for sustainability integration in early product development phases, through addressing the following research questions: How can strategic sustainability criteria and indicators be identified and connected to concept data about product engineering characteristics? How can the strategic sustainability implications of different product concepts be visualised and compared in early phases of product innovation?

\section{Background}

\subsection{Sustainable Product Development and the Sustainability Design Space}

Integrating the breadth of sustainability into product development is labelled sustainable design or sustainable product development (SPD) (Gagnon et al., 2012), which means that a strategic sustainability perspective is integrated and implemented into the early phases of product innovation, including life-cycle thinking (Hallstedt and Isaksson, 2017). Implementing sustainability in the early phases, i.e. in the design stages, means to provide opportunities for improving socio-ecological aspects of a product and for enhancing product competitiveness (Chiu and Chu, 2012).

Hallstedt (2017) presents an approach for how a Sustainability Design Space (SDS) can be defined using an approach that combined forecasting and backcasting to identify leading sustainability criteria and indicators. The SDS has several purposes: i) to represent the most important sustainability aspects that can be accomplished within the time constrained early development situation; ii) to be used as input for simulation and modelling for sustainability (Jaghbeer et al., 2017); iii) to inform sustainability models to be used in an automated decision support environment (Bertoni et al., 2018a); iv) to enable performance evaluation against the identified sustainability criteria (Watz and Hallstedt, 2018). The selected indicators need to be in line with the industry strategic long-term development criteria and set the basis for quantification of sustainability consequences related to different concept design cases. An indicator makes it possible to compare and measure the relative differences between solutions. Therefore, to understand how a concept solution influences social- and environmental sustainability throughout its whole life-cycle, a key step is to identify the sustainability design space for a product.

\subsection{Sustainability integration in concept design simulation and evaluation}

To include sustainability together with other engineering aspects in concept design has been a challenge for many years. In practice, there are commercialised computer aided design (CAD) tools available on the market that consider and visualise environmental impacts of different design solutions, for example, SolidWorks Sustainability (SolidWorks, 2019) and Eco Materials Adviser in Autodesk Inventor (Autodesk Inc, 2019). These tools focus mainly on general environmental impacts incurred by a product concept, such as: energy consumption, carbon footprint, water eutrophication, and sometimes social and economic 
aspects, such as: hazardous substances, end of life, raw material cost. However, these tools do not include a strategic long-term perspective as they only focus on specific, current and well-known environmental impact categories and not on future desired targets from both social- and ecological perspectives. This means that other sustainability impacts generated from the product solution may be omitted and no design guidelines are given to support development towards more sustainable solutions.

In line with sustainable product development, value driven design (VDD) is an area where both quantitative and qualitative design criteria are considered for evaluating the concept design space (Bertoni et al, 2018b). The areas of SPD and VDD are now becoming mature enough to be combined with more advanced simulation methods and modelling (Bertoni et al., 2018a), such as life-cycle simulations based on a Discrete Event approach (Bertoni et al., 2019). In the review article by Moon (2017) several application areas for simulation methods are analysed. Based on that study, it is concluded that simulation models can assist in an understanding of the sustainability, risk and value consequences of a decision. As simulation models have been proven to be a promising and efficient approach for product development decisionmaking, the research presented in this paper aims to propose a decision-support method which can be connected to and complement a simulation-driven model-based approach. Thereby, the challenges mentioned by Isaksson et al. (2015) in transferring and translating qualitative sustainability data to quantitative data, based on the relationship of engineering characteristics, can be tackled.

\section{Methodology}

According to the Design Research Methodology (DRM) (Blessing and Chakrabarti, 2009), design research can be structured in a number of iterative stages, including research clarification, descriptive study I, prescriptive study, and descriptive study II. This paper focuses on the results from a prescriptive study, where the increased knowledge based on earlier research phases was used to develop a support to change the current situation towards a desired one. The development of the decision-support was conducted through an action research based approach that combines research- and problem-solving interests (McKay and Marshall, 2001) through interactive and iterative works with practitioners. The case company in collaboration was an aerospace engine component development and manufacturing company.

The research process (Figure 1) can be described as follows: firstly, an understanding of the research gap and the industrial problem, as well as the synergistic overlap between these two was established. This mutual understanding was a natural result of the long-term collaboration with multiple descriptive and prescriptive studies with the company (Hallstedt and Nylander, 2019), complemented by review of literature and existing tools. As a result, it was decided to develop a new design method, and its requirements and necessary functions were clarified. To allow effective and efficient use of the method, a digital tool was developed in parallel. The longer-term goal of this research is to create a decision-making environment where sustainability, risk, and value aspects can be included in simulation. The support developed at this stage focused on the core functionality in terms of sustainability integration and connection of indicators to engineering characteristics for concept selection. Secondly, data was gathered at and together with the company, primarily through document review and interviews, e.g. in relation to the sustainability criteria of the company's sustainability design space (Hallstedt, 2017). Thirdly, support development took place in parallel, resulting in the proposed decision-support method. A prototype of a digital tool which was developed based on data from the aerospace company. Microsoft Excel was used as the means to create data models and run simulations. Fourthly, an initial support evaluation was conducted through a 60-minute-long focus group session, where the approach was presented to eight participants at the aerospace company. The participants included intended users, such as R\&D method specialist, robustness engineer and sustainability manager. They were asked to provide feedback on the proposed support and to answer a questionnaire with seven open-ended questions and fourteen closed-ended Likert scale questions. The open-ended questions were used to elicit the participants' opinions on the usability of the proposed support and to gather input for further needs and development. The closed-ended questions were used as a supplementary method to collect the perceived potential benefits brought by the proposed support. Six questionnaire samples were collected. Even though described here as four consecutive steps, it should be stressed that the process was highly iterative with multiple micro-cycles between the different phases. 

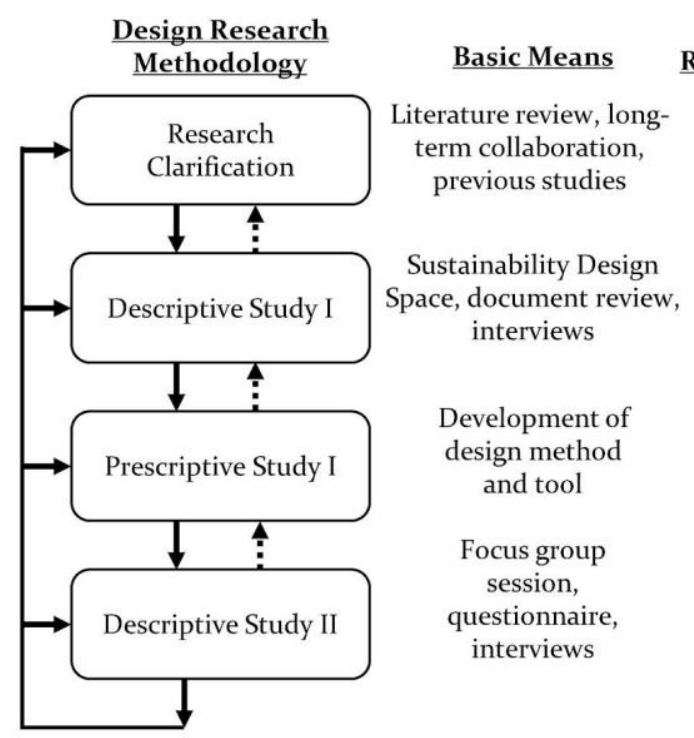

Action Research Based Approach

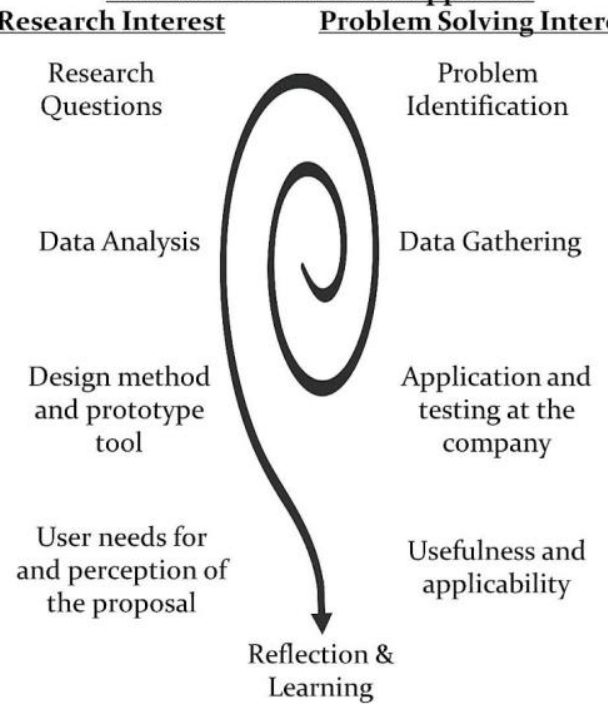

Figure 1. The research approach for development of the decision-support

\section{Results}

\subsection{Proposing the SCADS approach}

This paper proposes a novel decision-support called Sustainability Criteria And product life cycle Data Simulation (SCADS), to be used in the early stages of product innovation. It aims to help explore the potential sustainability impact from different product design concepts in a simulation driven environment. The SCADS approach consists of two parts: i) a decision-support method that integrates sustainability indicators using a strategic approach and connects them with engineering characteristics for concept simulation and selection (Figure 2), as well as ii) a prototype of a digital tool.

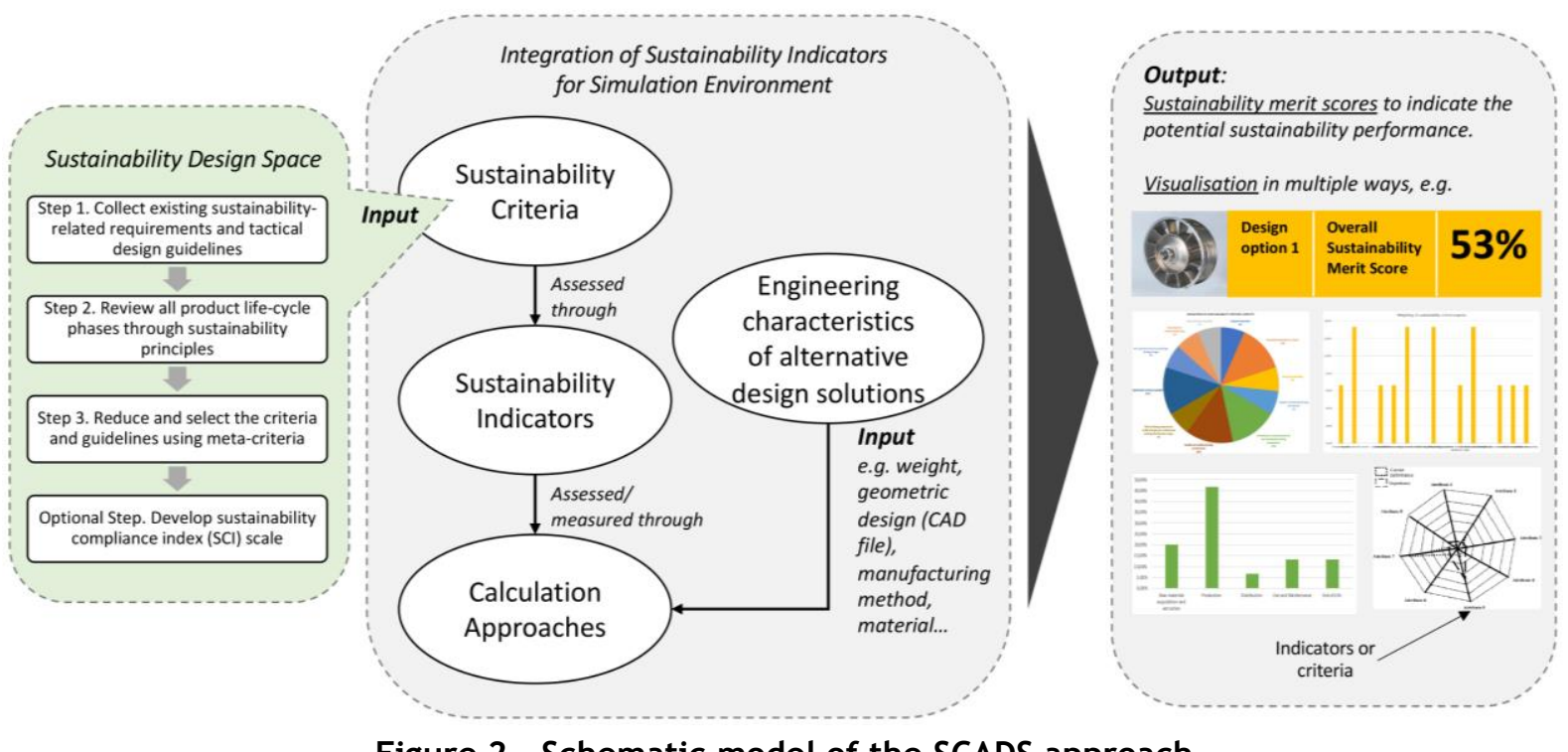

Figure 2. Schematic model of the SCADS approach

The proposed decision-support method can be applied generally by product development companies from any industry. It includes guidelines on procedures for tailoring the digital tool so that it can be adapted to the needs of different industries or specific companies, since the relevant sustainability criteria and indicators may differ from one industry/company to another. This section presents both the SCADS decision-support method and the prototype digital tool that was developed with the aerospace company. With SCADS a "sustainability merit score" can automatically be calculated for each design 
concept and thereby gives an indication of the sustainability performance for each concept. Figure 2 shows the schematic model with the four steps of the proposed design method:

1. Identifying sustainability criteria using Sustainability Design Space, and identifying relevant sustainability indicators;

2. Identifying the relevant engineering characteristics;

3. Defining the calculation approach for the sustainability indicators;

4. Calculating the sustainability merit score.

\subsubsection{Identifying sustainability criteria using Sustainability Design Space and identifying relevant sustainability indicators}

The Sustainability Design Space (SDS) method was used to identify the relevant sustainability criteria for the case company. There were three steps within the SDS process, and an optional fourth step that was also adopted to guide the development of a qualitative measurement scale for the criteria, called the sustainability compliance index (SCI) (Hallstedt, 2017):

- Step 1. Collect existing sustainability-related requirements and tactical design guidelines

- Step 2. Review all product life-cycle phases through sustainability principles

- Step 3. Reduce and select the criteria and guidelines using meta-criteria

- Step 4. Develop sustainability compliance index (SCI) scale

Twenty-two concrete and specific sustainability criteria were identified for the aerospace manufacturing company. The selection was downsized to eleven leading criteria which are characterised by i) data and information availability; ii) coverage of socio-ecological and economic sustainability dimensions; and iii) aspects that affect the concept design and that will be hard and costly to change later on (Hallstedt and Isaksson, 2017). Sustainability indicators are defined as measurements or facts (qualitative or quantitative) that indicate the state or level of the strategic socio-ecological leading sustainability criteria. To assess the concept performance in relation to the eleven leading sustainability criteria (Table 1), fifteen sustainability indicators were identified for the case company with the intention to achieve necessary, sufficient, concrete and non-overlapping coverage of the criteria.

Table 1. Examples of leading sustainability criteria, sustainability indicators (adapted from Watz and Hallstedt, 2018) and how they can be calculated

\begin{tabular}{|l|l|l|}
\hline Sustainability criteria & \multicolumn{1}{|c|}{ Sustainability indicators } & \multicolumn{1}{|c|}{ Indicator calculation approach } \\
\hline $\begin{array}{l}\text { 1. Avoid critical } \\
\text { materials }\end{array}$ & $\begin{array}{l}\text { 1. Material criticality of the product } \\
\text { concept }\end{array}$ & $\begin{array}{l}\text { Material criticality }(10 \text { - SCI level }) * \text { SCI } \\
\text { score * mass of critical materials used }\end{array}$ \\
\hline $\begin{array}{l}\text { 2. Use recycled } \\
\text { materials as input }\end{array}$ & 2. Amount of recycled materials used & \% of mass of recycled input materials \\
\hline 3. Scrap recyclability & 3. Recycling rate of scrap & $\begin{array}{l}\text { Recycling rate of scrap (\%) }=\text { amount of } \\
\text { scrap material recycled / total amount of } \\
\text { scrap }\end{array}$ \\
\hline $\begin{array}{l}\text { 4. Health and safety } \\
\text { during production stage }\end{array}$ & $\begin{array}{l}\text { 4. Risk of exposure or leakage (e.g. } \\
\text { leakage of chemicals, radiation } \\
\text { exposure) }\end{array}$ & From 1 to 10, based on statistics \\
\hline
\end{tabular}

\subsubsection{Identifying the relevant engineering characteristics}

A concept map (Figure 3) was drawn with the aim to identify the engineering characteristics of the product design and to understand the system boundary and the connections between the sustainability criteria. Each blob in Figure 3 represents a sustainability criterion identified for the case company. Desired engineering characteristics to be chosen for the development of the SCADS digital design tool should i) be related to these sustainability criteria and be influential to the results of the indicators; ii) be connected to the product solution design concepts; and iii) be relevant and changeable in the early stage of design process. For the aerospace company, three types of engineering characteristics were identified to be relevant to all of the eleven sustainability criteria, namely manufacturing methods, materials and geometric 
design. Within each type, there could be a detailed list of measurable engineering characteristics, for example, within 'geometric design' there could be volume, dimension, surface area, etc. It is believed that these three types of engineering characteristics would be generally relevant for product development by any company. However, this does not mean that this list is exhaustive. It is possible that for another company case, other engineering characteristics should be included because other leading sustainability criteria were identified due to differences in the design and manufacturing process.

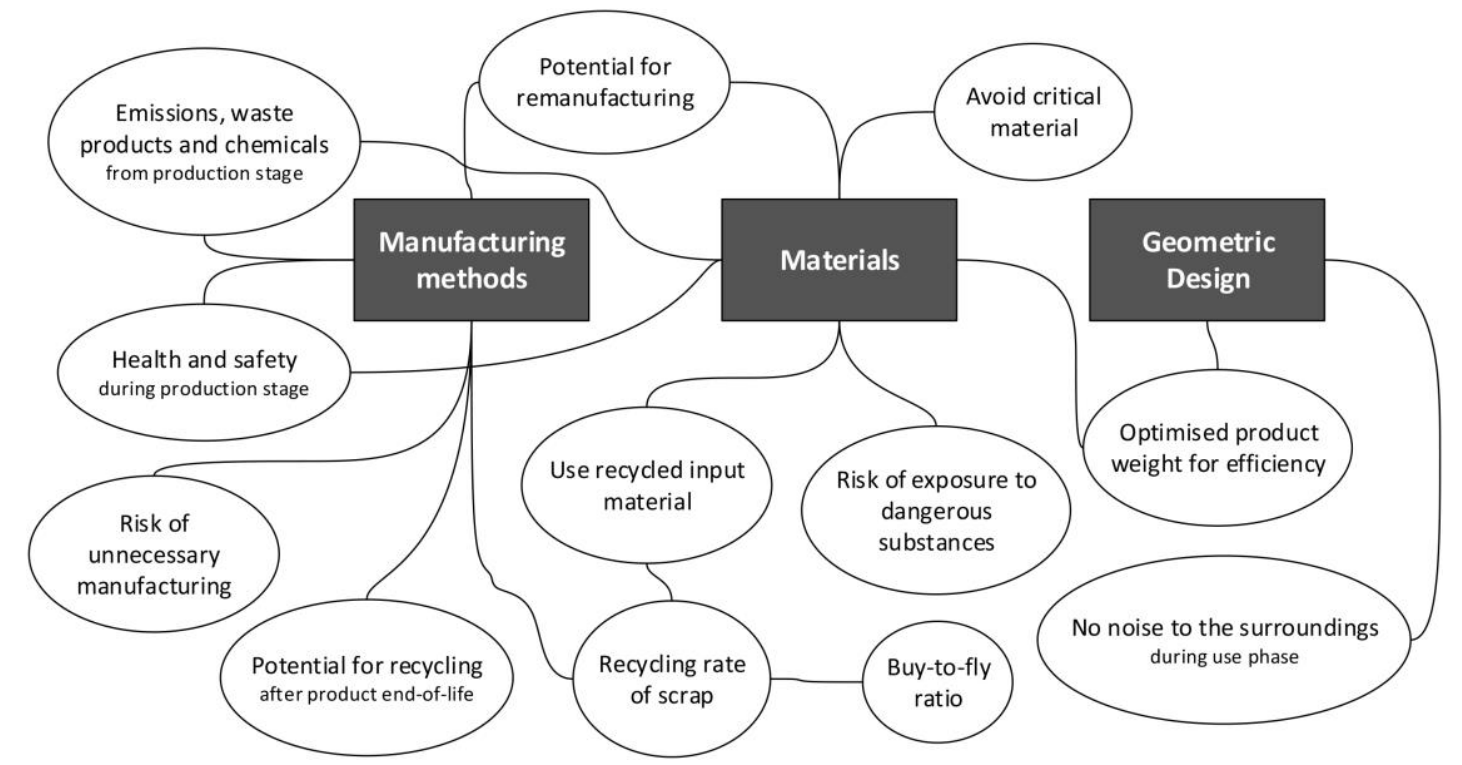

Figure 3. Concept map connecting the sustainability criteria to engineering characteristics

\subsubsection{Defining the calculation approach for the sustainability indicators}

The calculation approach for each sustainability indicator consists of specification of the input data, output and the function that relates the input to the desired output. The input data usually involves some of the mentioned engineering characteristics, i.e. materials, manufacturing operations, design, and other data retrieved from databases, such as life-cycle assessment (LCA) databases. If the required database does not exist already, then the required data, e.g. related to manufacturing and sustainability performance of the company's practice, needs to be collected. In the prototype SCADS digital tool reported in this paper, the databases were created in spreadsheets in Microsoft Excel.

\subsubsection{Calculating the sustainability merit scores}

This final step results in an overall sustainability merit score for each concept alternative. In our proposal, the computation happened in a simulation environment provided in the SCADS digital tool, which was developed based on the understanding gained from completing the first three steps of the SCADS design method (Figure 2). To demonstrate the SCADS approach, a prototype digital tool was developed for the case company. This prototype allowed manual input of engineering characteristics for numerous design concepts, processed the input in relation to databases created in the spreadsheet, and enabled real-time display of sustainability merit scores for the design concepts. Figure 4 gives an overview of the input, processes and output of the prototype digital tool.

Before the digital tool was used for the first time, the user needed to pre-set the weighting of the sustainability indicators. These relative weights reflected the importance of the associated sustainability criteria to the user company. The digital tool can be used to simulate sustainability performance for numerous design options. For this prototype, the user needed to manually input how many design options would be computed, and input data about their engineering characteristics such as material, weight and manufacturing methods. To calculate the merit rating for each sustainability indicator, a function module was created and connected to i) the input model containing engineering characteristics of the design options, and ii) database(s) storing data related to the parameters needed for each indicator, as explained in the third row of Figure 4. It is anticipated that the future version of 
the SCADS digital tool could be connected to CAD and/ or value-driven simulation tools. Then, the geometric design, as well as other attributes such as material and weight of the design option could be read from the CAD file or other external databases.

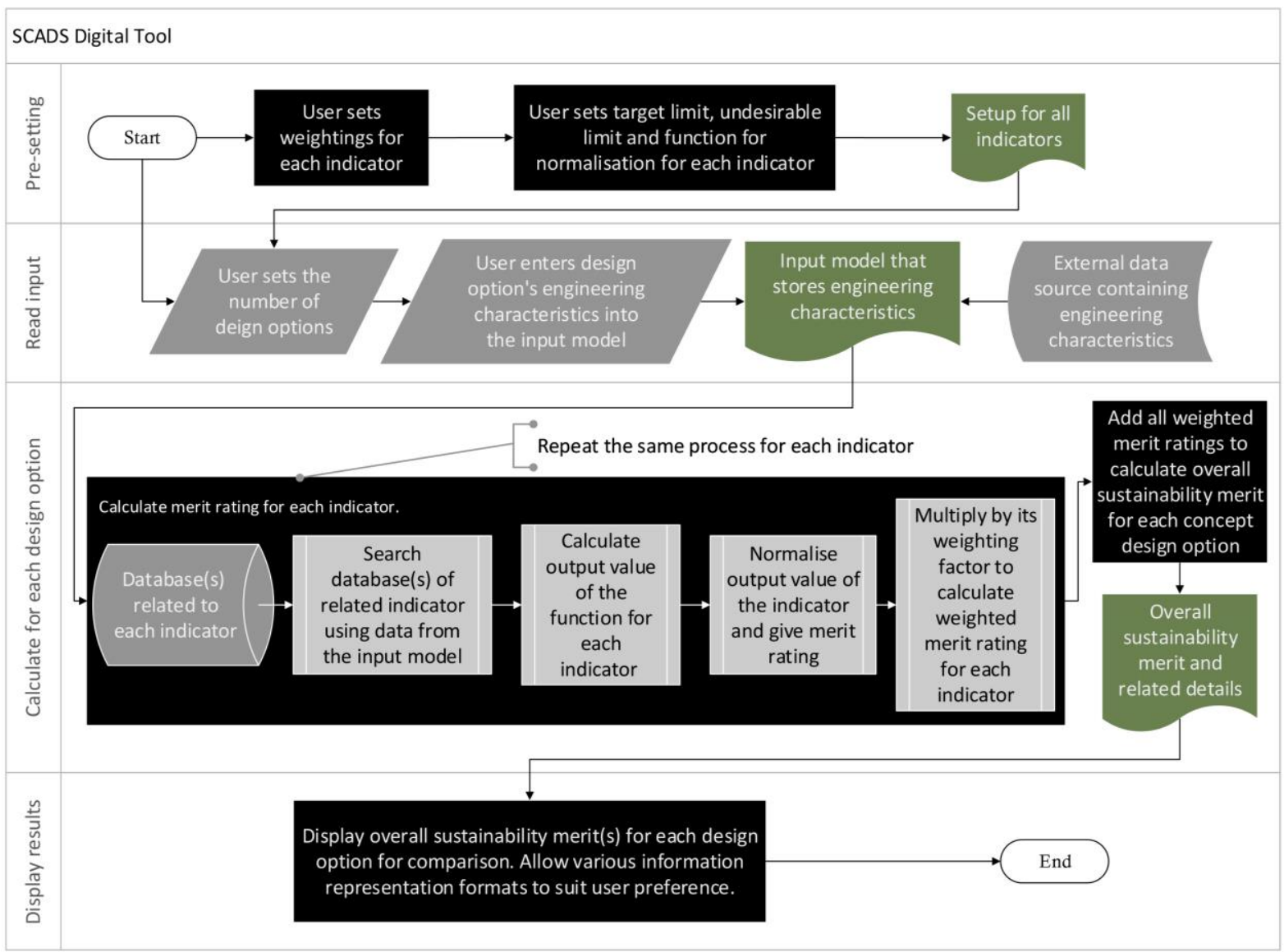

Figure 4. Flowchart of the prototype digital tool

To give meaningful and comparable results, the output value of the function for each indicator had to be normalised. Before first use, the design team needed to pre-set the target score, undesirable score and the function for normalisation for each indicator. This setup process might require technical knowledge from experts. For each indicator, a specific mathematical function was then used to convert the indicator output value into a percentage that showed how the concept performed relative to the defined interval. This percentage was called 'merit rating' in the prototype digital tool.

Fifteen sustainability indicators were included in the prototype, so fifteen merit ratings were generated by running a similar process for fifteen indicators using different function modules and databases. Then, a weighted sum model was used to calculate the overall sustainability merit score which equalled to the weighted sum of all the merit ratings for each design concept. This process can be run for a range of design concepts with varied engineering characteristics. The user could then compare the product design solutions based on their overall sustainability merit scores. For different situations and needs for decision-making, different information visualisation methods can be used. For example, one single score can be displayed for each concept design option to enable overall comparison between the sustainability performance of different concepts; or a breakdown of the sustainability merit can be shown to indicate the product performance associated to different sustainability aspects or life-cycle phases (see Figure 2).

\subsection{Feedback from industry}

The focus group discussion and the survey at the aerospace case company provided some early feedback on the proposed SCADS approach on perceived usefulness in relation to different needs, success factors for implementation in practice, visualisation of results and main limitations. 
The main benefit that the practitioners highlighted was that SCADS could be used to compare different concepts in relation to e.g. different materials or manufacturing methods, which could result in a "better and more holistic picture of alternative solutions' sustainability impact". While there were already existing tools that could be used for comparison purpose, the respondents saw a particular value in the "usability early in the development process", since "the earlier the method is applied, [...] the bigger the effect".

Four themes emerged from the responses for the open-ended questions related to success factors for usefulness and adoption of the proposed tool: (i) commitment and a sense of involvement and ownership at the company; (ii) easy to learn and use; (iii) a connection to company driving forces, such as economic benefit or strategic fit, to also create a management interest and request for the results of this method; and (iv) the degree to which the method can be tailored to the company's individual needs.

The respondents expressed different ideas on how the results should be visualised, but there was a consensus that there should be different options that the user could choose based on the context and needs. This could include tailored visualisations of the results for different life-cycle stages, for the social and environmental dimension of sustainability, or in relation to company specific requirements. Whether or not a single value was used as a visualisation option, it should be possible to "easily identify if a result is good or bad".

The fact that both qualitative and quantitative data needed to be analysed together in the SCADS digital tool was seen as a challenge. Furthermore, the method's strength in terms of including a strategic and holistic perspective on sustainability also came with drawbacks: it entailed a higher level of complexity, making the method more difficult to learn and understand, which in turn decreased transparency and trustworthiness of the result, and increased the resources needed for implementation. A point of criticism and idea for further development was the weighting of different sustainability indicators, which in its current form was considered as too subjective and arbitrary. To overcome some of these limitations, the respondents recommended to test the SCADS digital tool for an already developed product concept with real data and to provide information and education on the method and its benefits. Besides, connecting the results to technical requirements and including more options for variations, e.g. switching between countries or electricity mixes, were mentioned as recommendations for further development.

The ratings for the close-ended questions showed that the proposed method was perceived as a very good support for (i) comparing different design concepts from a sustainability perspective; (ii) including sustainability aspects alongside other aspects in overall concept evaluation and selection; (iii) giving support in trade-off situations in concept selection; (iv) understanding what sustainability means for the company's products; and (v) getting a picture of the sustainability impact across different life-cycle stages. In its current form, it was seen as less useful for showing the business case for sustainability and for making detailed optimization simulations.

\section{Concluding discussion}

Product development companies play a key role in the transition towards sustainability. There is a need to get a clearer picture of the sustainability implications of different design concepts during the early phases of product development, as a product's sustainability impact and interaction with larger social system are largely determined at these phases. Building on knowledge gained from a long-term research collaboration with an aerospace product development and manufacturing company, this paper proposes the Sustainability Criteria And product life-cycle Data Simulation (SCADS) approach. The proposed approach, consisting of a decision-support method and a digital tool, offers key features that:

- guide strategic and systematic integration of sustainability criteria and indicators into design simulation;

- visualise sustainability implications holistically and enable concept comparison and selection in early design stages;

- incorporate all three dimensions of sustainability, namely ecological, social and economic;

- give support in trade-off situations in concept selection;

- use backcasting, thus include a long-term strategic sustainability perspective; 
- can be customised and tailored for the specific characteristics of companies;

- can be integrated to and complement value-driven simulation tools with a sustainability perspective based on both qualitative and quantitative criteria and the relationship of the engineering characteristics.

A focus group and a survey were conducted as pilot study to get some early feedback on the proposed support. Positive responses were received from industry practitioners regarding the proposed support's usability in early product development phases for supporting sustainable design. The trustworthiness of the results is however limited by the small sample size.

Lessons learned from developing this initial prototype of the SCADS digital tool facilitate deeper understanding of the challenges in integrating sustainability into practical design tools and lay the groundwork for future development. The lack of data of the product's sustainability performance poses a major challenge for developing the SCADS digital tool. It leads to the difficulty in defining accurate calculation method for the sustainability indicators and in defining the normalisation functions. Continuous research is needed to collect and manage data systematically to fill this knowledge gap. In the presented prototype, positive and negative linear functions were adopted to normalise the indicator values which was a simplified representation of reality. More sophisticated statistical models need to be developed to render more realistic simulation of product's sustainability implications. Similarly, deeper understanding of external factors can contribute to refinement of the weighting method of the tool, so that the sustainability merit scores align with customer and other stakeholder values. For instance, customer demands and preference for sustainable product features can be considered when setting the weights of sustainability indicators. Or the tool can incorporate sustainability risk-value perspectives for supporting business decisions related to trade-off situations and company's long-term success.

Furthermore, future research needs to delve deeper into utilising the SCADS method by connecting the SCADS digital tool to other value-driven simulation and/or CAD tools. More intuitive user experience and decision-making processes can be realised by automatic information retrieval and interactive data visualisation. For example, the sustainability merit scores can vary instantaneously when the geometric design of the product is adjusted, as the adjustment may drive changes in relevant parameters such as product weight and material. Another direction of potential development is to develop simulation-based optimisation, for example instead of entering product engineering characteristics manually, product concepts can be generated and selected automatically using artificial intelligence. For designing effective and engaging data visualisation, further user-centred interface design research is needed to understand user perception of sustainability information and indicators, for example on adaptive information representations and usability.

\section{Acknowledgements}

Financial support from the Knowledge Foundation in Sweden is gratefully acknowledged. Sincere thanks to the industrial research partners.

\section{References}

Ahmad, S. et al. (2018), "Sustainable product design and development: A review of tools, applications and research prospects", Resources, Conservation \& Recycling, Elsevier, Vol. 132 No. October 2017, pp. 49-61. https://doi.org/10.1016/j.resconrec.2018.01.020

Autodesk Inc. (2019), "Eco Materials Adviser", Autodesk App Store, available at: https://apps.autodesk.com/ INVNTOR/en/Detail/Index?id=8391666263963684768\&appLang=en\&os=Win64 (accessed 1 October 2019).

Bertoni, A. et al. (2018a), "Model-based decision support for value and sustainability assessment: applying machine learning in aerospace product development", Proceedings of the DESIGN, 2018, The Design Society, Glasgow, pp. 2585-2596. https://doi.org/10.21278/idc.2018.0437

Bertoni, M., Bertoni, A. and Isaksson, O. (2018b), "EVOKE: A Value-Driven Concept Selection Method for Early System Design”, Journal of Systems Science and Systems Engineering, Vol. 27 No. 1, pp. 46-77. https://doi.org/10.1007/s11518-016-5324-2

Bertoni, M. et al. (2019), "Life cycle simulation to support cross-disciplinary decision making in early PSS design”, Procedia CIRP, Vol. 83, pp. 260-265. https://doi.org/10.1016/j.procir.2019.03.138 
Blessing, L. and Chakrabarti, A. (2009), DRM, a Design Research Methodology, Springer, London, New York. https://doi.org/10.1007/978-1-84882-587-1

Bovea, M.D. and Pérez-Belis, V. (2012), "A taxonomy of ecodesign tools for integrating environmental requirements into the product design process", Journal of Cleaner Production, Elsevier Ltd, Vol. 20 No. 1, pp. 61-71. https://doi.org/10.1016/j.jclepro.2011.07.012

Broman, G. et al. (2017), "Science in support of systematic leadership towards sustainability", Journal of Cleaner Production, Vol. 140, pp. 1-9. https://doi.org/10.1016/j.jclepro.2016.09.085

Byggeth, S. and Hochschorner, E. (2006), "Handling trade-offs in Ecodesign tools for sustainable product development and procurement", Journal of Cleaner Production, Vol. 14 No. 15-16, pp. 1420-1430. https:// doi.org/10.1016/j.jclepro.2005.03.024

Chiu, M.-C. and Chu, C.-H. (2012), "Review of sustainable product design from life cycle perspectives", International Journal of Precision Engineering and Manufacturing, Vol. 13 No. 7, pp. 1259-1272. https://doi.org/10.1007/s12541-012-0169-1

Gagnon, B., Leduc, R. and Savard, L. (2012), "From a conventional to a sustainable engineering design process: different shades of sustainability", Journal of Engineering Design, Vol. 23 No. 1, pp. 49-74. https://doi.org/ $10.1080 / 09544828.2010 .516246$

Gaziulusoy, A.İ., Boyle, C. and McDowall, R. (2013), "System innovation for sustainability: a systemic doubleflow scenario method for companies", Journal of Cleaner Production, Vol. 45, pp. 104-116. https:// doi.org/10.1016/j.jclepro.2012.05.013

Hallstedt, S.I. (2017), "Sustainability criteria and sustainability compliance index for decision support in product development", Journal of Cleaner Production, Vol. 140, pp. 251-266. https://doi.org/10.1016/j.jclepro. 2015.06.068

Hallstedt, S.I. and Isaksson, O. (2017), "Material criticality assessment in early phases of sustainable product development", Journal of Cleaner Production, Elsevier Ltd, Vol. 161, pp. 40-52. https://doi.org/ 10.1016/j.jclepro.2017.05.085

Hallstedt, S.I. and Nylander, J.W. (2019), "Sustainability Research Implementation in Product Development Learnings from a Longitudinal Study", Proceedings of the Design Society: ICED, Vol. 1, Cambridge University Press, pp. 3381-3390. https://doi.org/10.1017/dsi.2019.345

Held, M. et al. (2018), "Current challenges for sustainable product development in the German automotive sector: A survey based status assessment", Journal of Cleaner Production, Vol. 195, pp. 869-889. https://doi.org/10.1016/j.jclepro.2018.05.118

Isaksson, O. et al. (2015), "Model based decision support for value and sustainability in product development", Proceedings of the Design Society: ICED, Vol. 1, pp. 21-30.

Jaghbeer, Y. et al. (2017), "Exploration of Simulation-Driven Support Tools for Sustainable Product Development", Procedia CIRP, The Author(s), Vol. 64, pp. 271-276. https://doi.org/10.1016/j.procir.2017. 03.069

Kwok, S.Y. and Hallstedt, S.I. (2018), "Towards Strategic Sustainable Product Development: Challenges and Opportunities for Communicating Sustainability in a Value Chain”, Norddesign 2018 Conference, pp. 1-14.

McAloone, T.C. and Tan, A.R. (2005), "Sustainable product development through a life-cycle approach to product and service creation: An exploration of the extended responsibilities and possibilities for product developers", Proceedings of Eco-X Conference: Ecology and Economy in Electronix, KERP, Vienna, pp. 1-12.

McKay, J. and Marshall, P. (2001), "The dual imperatives of action research", Information Technology \& People, Vol. 14 No. 1, pp. 46-59. https://doi.org/10.1108/09593840110384771

Moon, Y.B. (2017), "Simulation modelling for sustainability: a review of the literature", International Journal of Sustainable Engineering, Vol. 10 No. 1, pp. 2-19. https://doi.org/10.1080/19397038.2016.1220990

Schöggl, J.-P., Baumgartner, R.J. and Hofer, D. (2017), "Improving sustainability performance in early phases of product design: A checklist for sustainable product development tested in the automotive industry", Journal of Cleaner Production, Vol. 140, pp. 1602-1617. https://doi.org/10.1016/j.jclepro.2016.09.195

Schulte, J. and Hallstedt, S. (2017), "Challenges and preconditions to build capabilities for sustainable product design", Proceedings of the Design Society: ICED.

Schulte, J. and Hallstedt, S. (2018), "Company Risk Management in Light of the Sustainability Transition", Sustainability, Vol. 10 No. 11, pp. 4137. https://doi.org/10.3390/su10114137

SolidWorks. (2019), "SolidWorks Sustainability", available at: https://www.solidworks.com/sustainability/ (accessed 1 October 2019).

United Nations. (2015), Transforming Our World: The 2030 Agenda for Sustainable Development. United Nations Sustainable Knowledge Platform, Resolution Adopted by the General Assembly on 25 September 2015.

Watz, M. and Hallstedt, S.I. (2018), "Integrating Sustainability in Product Requirements", Proceedings of the DESIGN 2018, Vol. 3, The Design Society, Glasgow, pp. 1405-1416. https://doi.org/10.21278/idc.2018. 0377 